WIENER SLAVISTISCHES JAHRBUCH, Band 57/2011, 37-51

\title{
Das Gedicht „Hlasy“ von Ján Ondruš im Kontext der jungen slowakischen Poesie der späten 1950er und frühen 1960er Jahre. Thematologische und gattungspoetische Überlegungen ${ }^{1}$
}

Der slowakische Dichter Ján Ondruš (1932-2000) begann im Jahr 1956 in der soeben gegründeten Zeitschrift für junge Literatur „Mladá tvorba“ intensiv zu publizieren. In der zweiten Hälfte der 1950er Jahre, als eine neue Generation und im engeren Sinne auch Gruppe von Autoren wie Ján Stacho, Jozef Mihalkovič und anderen antrat, sich zur „Trnavská skupina“ zusammenfand und „Konkretisti“ nannte, spielte Ondruš menschlich wie künstlerisch die Rolle eines Initiators. Infolge editorischer Querelen und komplizierter biographischer Umstände erschien seine erste selbständige Buchpublikation jedoch erst im Jahr 1965, und zwar der Gedichtband des Jahrzehnts, „Šialený mesiac“ (Der verrückte Mond). Die zuvor in Zeitschriften veröffentlichten und im Debüt nicht enthaltenen Arbeiten nahm der Dichter Štefan Strážay 1982 in den Auswahlband „Pamät““ (Das Gedächtnis) auf, den er zu Ondrušs 50. Geburtstag zusammenstellte. Damit machte er auf die damals noch nicht ins allgemeine Bewusstsein gedrungene Originalität von Ondrušs frühen Versen und zugleich auf die Impulse aufmerksam, die sie der slowakischen Poesie in der zweiten Hälfte der 1950er Jahre verliehen hatten. Für die künstlerischen Wandlungsprozesse und Veränderungen jener Zeit bürgerten sich im slowakischen Diskurs der letzten

${ }^{1}$ Zwei Arbeiten von Pavol Winczer haben die Wahl dieses Themas angeregt: Ende der 1960er Jahre widmete sich Winczer im Rahmen seiner slowakistischen Interessen der Poesie von Ján Ondruš mit einer exemplarischen Analyse des Gedichts „Studňa“ (Der Brunnen) (vgl. Winczer 1968); Anfang der 1980er Jahre übersetzte er aufgrund seiner polonistischen Kompetenz eine bis heute inspirierende Studie von Czesław Zgorzelski über die Möglichkeiten der gattungspoetischen Erfassung der zeitgenössischen Dichtung und machte sie damit dem slowakischen literaturwissenschaftlichen Publikum zugänglich (vgl. Zgorzelski 1981). Die Übersetzungen aus dem Slowakischen stammen, wenn nicht anders angegeben, von Ute Raßloff. 
Jahrzehnte zumindest provisorisch auch die Begriffe Neo- oder Postavantgarde ein. Als Peter Zajac im Jahr 2000 die Geschichte der slowakischen Literatur für ein internationales Publikum essayistisch als „Abenteuer“ skizzierte, schrieb er über die Dichter der Trnavská skupina: „Celá skupina žila riskantne, na ostrí noža. Jána Ondruša, azda najtalentovanejšieho básnika skupiny, postihol hölderlinovský osud“ (Die ganze Gruppe lebte riskant, auf des Messers Schneide. Ján Ondruš, den wohl talentiertesten Dichter der Gruppe, ereilte das Schicksal Hölderlins) (Zajac 2004: 75).

Das Gedicht „Hlasy“ (Stimmen) erschien erstmals 1962 in der Zeitschrift „Slovenské pohl'ady“ (vgl. Ondruš 1962). ${ }^{2}$ Im Folgenden soll zumindest ein provisorischer Gang durch das Gedicht unternommen werden, um einige Aspekte seines komplexen Bedeutungsgeflechts einzufangen. Diese Methode wird schon durch die Gliederung des aus mehr als achtzig Versen bestehenden Textes vorgegeben. Sporadische Exkurse sollen überdies die Vernetzung des Gedichts mit dem zeitgenössischen Diskurs andeuten und somit seine Wahl auch für weiterführende interpretatorische und literaturgeschichtliche Überlegungen legitimieren.

Der Titel „Stimmen“ kündigt ein phonisch-vokalisch-musikalisches Thema an. Ergänzt wird es durch das retrospektive Thema der Erinnerung im Sinne von „Stimmen aus der Vergangenheit", und schließlich legen die weiteren Transformationen von Ondrušs Poesie nahe, auch schon an jenes phantomartig-halluzinatorische Thema zu denken, bei dem sich die "Stimmen“ in Persekutionsphantasmen verwandeln. ${ }^{3}$

Der Eingangsvers „Ich lege die Geige beiseite“ impliziert das Unter- oder Abbrechen einer musischen oder musikalischen Tätigkeit oder zumindest das Manipulieren mit einem zerbrechlichen Musikinstrument. Er leitet ein Verstummen ein, eine Situation des sich Vorstellens, sich Vergegenwärtigens eines Abwesenden. Der Gegenstand dieser Imagination ist der Großvater. Er ruft die Motivkette der Familie, des Geschlechts, der Generationenfolge, der „Weitergabe von Generation zu Generation" auf; die nähere berufliche Bestimmung „Schmied“ verweist wiederum auf die Motivik einer robusten, vitalen, physischen Arbeit - im möglichen Kontrast zur

${ }^{2}$ In der von Strážay besorgten Auswahl schließt es die Abteilung der vor dem Debüt erschienenen Gedichte ab. Diese sowie die zwischen 1965 und Anfang der 1970er Jahre in Buchform erschienenen Sammlungen und Kompositionen veröffentlichte Ondruš nach einer mitunter polemischen, radikalen Überarbeitung erneut im Auswahlband „Prehítanie vlasu“ (1996, Verschlucken des Haares).

3 Anm. d. Übers.: Schon in der ironisch-sarkastischen, im Sinne der Apollinaireschen Zone komponierten Dichtung „V stave žlče“ (1968, Im Zustand der Galle) unterliegt das gespaltene Subjekt einer zunehmenden Depersonalisierung. In der Komposition „Kl'ak“ (1970, Kniefall), die mittels Spiegelmagie eine halluzinatorische Szenerie aufbaut und in ihrer Metaphorik den Surrealismus zitiert, findet eine Dekomposition des Körpers statt. Das Subjekt imaginiert seine eigene Verwesung mit Bildern von Hautausstülpungen und mit der Fauna und Flora der Zersetzung. Die Sammlung „Mužské korenie“ (1972, Männliches Gewürz) enthält einen Zyklus mit sich selbst anredenden Du-Figuren wie dem Lästerer, Eigenbrötler, Blickausweicher, Zähneklapperer, Stillesucher, Speichler oder Seilgänger, dem nur noch der Fall ins Schwarze bevorsteht (vgl. auch Kindler ${ }^{3} 2009$ ). 
„Geige“ und zur musischen Betätigung. Und in der Tat entfaltet und bestätigt eine refrainartig wiederkehrende, selbstproblematisierende Frage diesen Kontrast. Das vergegenwärtigende „Ich sehe“ leitet die narrative Beschreibung der Arbeitsschritte beim Beschlagen eines Pferdes ein. Die Szene findet in der Hufschmiede statt, umringt von einem Chor von „Gaffern“; poetologisch handelt es sich um eine Klimax, um eine Steigerung der ekstatischen Arbeitsaktivität mit dem Spiegelbild der Antiklimax, wenn der Leser erfährt, wie er „,aufhörte / fortging / sich niederlegte“. Die wiederkehrende selbstproblematisierende Frage, die unter Auslassung von Wendungen wie „gibt es“ elliptisch formuliert wird, enthält den „Splitter“, als hätte dieser aus einem Abstand von Jahren nun das „Auge“ des sich Erinnernden erreicht; es könnte sich aber auch um die diskrete Paraphrase eines feucht werdenden Auges handeln, um eine Träne, die mit einer verstohlenen Geste aus dem Auge gewischt wird, um die Rührung beim Heraufbeschwören der Vergangenheit zu verbergen; und schließlich böte sich hier auch eine Stelle aus dem Neuen Testament an, wo die anmaßende Beurteilung des Anderen verurteilt wird: „Warum siehst du den Splitter im Auge deines Bruders, aber den Balken in deinem Auge bemerkst du nicht?" (Mt. 7, 3). Träfe das zu, dann wäre die zitierte Passage schon als individuelle und radikale Umwertung zu verstehen, der „Splitter“ im eigenen Auge wäre ein Synonym für das Defizitäre, für Schwäche und Schuldgefühle, während der damit korrelierende „Balken“ als Synonym für Kraft, für bewältigtes Leben erschiene ... Es folgt eine szenische Darstellung des Endes mit Passagen in dramatisierender direkter Rede, mit Rufen und familiären „Trippelschritten“. In einem Staccato ohne Verben - ausgedrückt durch das Zustandsperfekt ,ausgestreckt“ und den oxymorischen Vergleich „schwarz wie das Feuer", der von der Schmiedearbeit kommt, ist vom Großvater die Rede. Die Zeichen des Endes (,zitterte im Schüttelfrost") werden mittels der Homonymie des Wortes „,cievka“ (Äderchen / Glühfaden) an die Glühlampe delegiert. Im Slowakischen kann mit dem Wort „,cievka“ der Glühfaden als technischer Bestandteil der Glühlampe und gleichzeitig das Blutgefäß im körperlichen, anatomisch-physiologischen Sinn aufgerufen werden, und zwar in der Diktion einer exakten Sachlichkeit. Alles Fatale wird durch eine gnomische Aussage definitiv: „Es ist das Lied, nach dem Lied ist das Schweigen“, wobei das Lied als Synonym für das Leben, für den Rhythmus des Lebens und der Arbeit steht ... Gegenüber der kompakten, reliefartigen Darstellung des „Großvaters“ wird der „Vater“, dem der sich Erinnernde zeitlich und lebensweltlich „näher“ zu stehen scheint, intensiver und detaillierter, fast wie ein „Genrebild“ ausgeführt: Es ist der Rhythmus des Arbeitstages, die Ekstase der Arbeit, der körperlichen Anstrengung, eine technisch-lautliche Orchestrierung oder Instrumentierung der Werkstatt mit gelegentlichen Übergängen in die Idylle des Häuslichen und einem wiederholten Durchbrechen in die ansonsten verbal verschwiegene Hektik des Lebens (,es wissen und nicht sagen: ich lebe, ich lebe ...") bis hin an die Grenzen der - wie man heutzutage sagen würde - ,häuslichen Gewalt" ... Die technische Einrichtung der Werkstatt (Pedal, Pfeife, Klänge, implizit auch der Blasbalg) wird hier direkt mit dem königlichen Musikinstrument der 
Kirche verglichen - mit der Orgel. Aus welchem Grund? Um den Zusammenhang zwischen Orgel und Schmiede zu erklären, muss man etwas weiter ausholen; zunächst sei auf eine elementare biographische Information über Ondruš verwiesen: „Er stammte aus einer Bauernfamilie, der Vater beherrschte auch das Schmiedehandwerk, die Mutter kümmerte sich um den Haushalt“ (Bokníková-Tóthová 2006: 577). ${ }^{4}$ Im Gedicht kommt neben der ,kleinen Zeit" der Autorenbiographie auch die "große Zeit" (Bachtin) der archaisch-mythischen Schichtungen zu Wort, die bisweilen unvorhersehbar (aus der Tiefe der Vergangenheit) an die Oberfläche einer auch weiter gefassten Gegenwart dringt. Bei der prägnanten Formulierung Mircea Eliades im Zusammenhang mit der „Mythologie der Eisenzeit“ drängen sich Assoziationen zu Ondrušs „Stimmen“ geradezu auf:

Außerdem hat dieser Gott-Schmied auch mit Musik und Gesang zu tun, wie auch in zahlreichen Völkern die Eisen- und Kupferschmiede zugleich auch Musiker, Dichter, Quacksalber und Magier sind. Auf verschiedenen kulturellen Ebenen (ein Zeichen hohen Alters) scheint also ein enges Band zwischen der Schmiedekunst, den okkulten Wissenschaften (Schamanismus, Magie, Heilkunst usw.) und den Künsten des Gesanges, des Tanzes und der Dichtung zu bestehen. (Eliade 1978: 60)

Das Stellvertreter-,,Objekt“ der erwähnten, potenziell aggressiven Gesten ist das Requisiteninventar der häuslichen Idylle, des Hauses, des Zuhause: „Küchentisch, Tassen und Zwiebel“, „Mauswinkel“, „Spitzen und Blümchen, / die gestickte Tulpe“. Diese Gegenstände bezeichnen einen traditionell eher ,weiblichen“ Raum, der einen Kontrast zur „Werkstatt“ bildet. - Die ganze Ekstase des Geschehens wird phonisch durch das „Türenknallen“ beendet, dem das „Verstummen“ folgt wie ein „Klacken der Klinke“, ein „Weinen“. Von der vergegenwärtigten Handlung geht der sich erinnernde Sprecher zu einem emphatischen dreifachen Kommentar über, der zwischen selbstproblematisierendem Seufzen und odischer Bewunderung oszilliert: „Ach, was für Lieder diese Menschen sangen! // Ach, wie klang in diesen Mündern der Gesang! // Wie er klang! Wie sich die Worte dieses Lieds zusammenbuken!“ Der Blickwinkel verengt sich vom „Lied“ und den „Menschen“ über den „Gesang“ in den „Mündern“ bis zu dem auch klanglich untermauerten, kompakten „Wie sich die Worte dieses Lieds zusammenbuken!“, was an die von Jurij Tynjanov beschriebene semantische Verdichtung des Verses denken lässt. Sie wird hier durch eine für Situationen mit „Feuer“ passende Benennung realisiert, zum Beispiel wenn Koks beim Heizen im Ofen zu einer unangenehm kompakten Masse verklebt ...

Hier ist vielleicht der Augenblick, um es mit dem Dichter zu sagen, der ,rechte Moment" gekommen, einen Exkurs über den Gesamtcharakter der bisher besproche-

${ }^{4}$ Das Wechselspiel von Elementarem und Metaphorischem ist ein Merkmal aller frühen Gedichte von Ján Ondruš. In diesem Zusammenhang sei daran erinnert, dass wir als Rezipienten eines lyrischen Textes die Neigung haben, spontan auf die metaphorische Bedeutungsebene überzugehen, wenn uns die faktischen, sachlichen Zusammenhänge entgehen, weil sie verdeckt oder widerständig sind. 
nen Textpassagen zu versuchen. Thematisch handelt es sich gewiss um „familiäre Verse“, um eine Ehrerweisung für die nächsten Angehörigen - für die epische und detaillierte Ausführung bietet sich hier die Bezeichnung „monumentalisierendes Porträtgedicht" an. Für dieses Genre gab es im Kontext der slowakischen Lyrik der späten 1950er Jahre Präzedenzfälle; so finden wir im Debüt „Až dozrieme“ (1956, Bis wir reif sind) von Milan Rúfus (1928-2009) das Mutter und Vater ehrende Gedicht „Vyznanie lásky“ (Liebeserklärung), die Gedichte „Otec“ (Vater) und „Pieseň o tkáčke" (Lied über die Weberin), ein rustikal-folkloristisch verbrämtes Bild der Mutter, oder das Gedicht „Genezis“ (Genesis), das ganz im Sinne des Titels den Ursprung des Autors und seine soziale Genealogie formuliert. Apostrophen, narrative Momente und Enumerationen sind in eine odische Rhetorik und pamphletartige Invektive integriert. Die so dokumentierte und deklarierte ,proletarische Herkunft“ verweist - neben der faktischen oder fiktiven Gültigkeit - literarisch vermutlich auf Jiří Wolker, dem Milan Rúfus, zur Zeit seines Debüts schon als Literaturwissenschaftler und Hochschullehrer tätig, den umfassenden Essay „Wolker v nás“ (Wolker in uns) gewidmet hatte. Ein weiterer Verweis führt zu Vojtech Mihálik (19262001), dem Autor des Gedichtbandes „Plebejská košel'a“ (1950, Das Plebejerhemd). Die bei Rúfus poetisch evozierten und rhetorisch exponierten Formen und Merkmale der „,entfremdeten Arbeit“ und der „Ausbeutung“, der nostalgische „Schleier längst vergangener Jahre“, das ,beklemmende Märchen ... von der Kindheit meiner Mama“ (Rúfus 1956: 77 und 84) und andere Stellen erlaubten es in der zweiten Hälfte der 1950er Jahre trotz des hochstilisierten lyrischen Personalismus, mit welchem der Autor dem zeitgenössischen Diskurs und dessen Normen polemisch die Stirn bot, seine Texte zum Thema der nächsten Angehörigen wenigstens teilweise im Zeichen einer ideologischen Instrumentalisierung zu lesen oder sie direkt für diesen Kontext zu vereinnahmen, während sie heute eine ideologiekritische Lektüre provozieren könnten, beispielsweise um die Ästhetisierung und Ethisierung des Plebejer- bzw. Proletariertums zu evidieren. Ondruš modellierte die Arbeit in seinen „Stimmen“ auf eine andere Art. Über ihre potenzielle soziale Markiertheit oder Typik hinaus verortete er sie in einer ekstatisch und pathetisch verstandenen, zutiefst dynamischen Existenz, die auch mit der Möglichkeit des Kollabierens, mit dem plötzlichen Ende rechnen muss. Dazu gibt es Parallelen bei anderen Dichtern der Trnavská skupina. Beispielsweise ließe sich das Gedicht „O cemente“ (Über den Zement) von Jozef Mihalkovič (1935) aus dessen Debüt „Lútost““ (1962, Mitleid) anführen, das eine dichterische Version von Arbeitsvorgängen enthält, wobei auffällt, dass Industriearbeit als Handarbeit dargestellt wird:

Smie miešat' kameň $\mathrm{s}$ hlinou [...].

Do hlín s láskou hrúži ruky l'udský tvor.

Preosiali zem, vyňali ju, v rukách zapálili, explozívnu, preletujúcu, jame odňatú.

Kým tlela, vnútri vzbíkli a nadobudli sily, mučili ju, mučili si ruky, vyhmatávajúc podstatu. (Mihalkovič 1962: 19) 
Er darf mischen den Stein mit dem Lehm [...] / In die Tonerde senkt die Hände mit Liebe das Menschengeschöpf. // Sie siebten die Erde durch, holten sie hoch, in den Händen entfachten sie diese, / die explosiv war, hin und her flog, der Grube entrissen. / Während sie schwelte, fingen sie innen Feuer und gewannen Kraft, / sie peinigten sie, sie peinigten ihre Hände, indem sie das Wesen ertasteten.

Ein lautlich instrumentiertes Beispiel für ekstatische Tätigkeit bietet auch das ansonsten eher „,chirurgisch“ nüchterne Gedicht „Z nemocnice“ (Aus dem Krankenhaus) aus Ondrušs Debütband. In einer aus wenigen Versen bestehenden imaginären „Enklave“ der Kindheit bzw. Jugend, die einen starken Kontrast zum Krankenhaus aufbaut, heißt es: „Kováči v rytme kopýt kladivami zvonia ...“ (Die Schmiede läuten die Hämmer im Hufeisenrhythmus ...) (Ondruš 1965: 48).

Doch kehren wir zu unserem Text zurück. Die Worte aus den Liedern wurden darin personifiziert. Sie haben sich emanzipiert, als hätten sie - analog zu ihrer Herkunft - eine unangemessene Expressivität erlangt: Sie „schlugen ins Gesicht, / rammten die Brust, stürzten um, trampelten“, aber sie können auch weich und zart sein: Sie , „ließen sich auch zur Antwort erweichen, fanden im Gras einen Pfad, / eine einzige Flaumfeder verfing sich in der Stimme, / schwamm, sank, flog aus dem Fenster / unter den fahlen Himmel, wo der Wind das Lied ausblies". Auch hier bietet sich ein Verweis auf den historischen Kontext an. Im Gedicht „Večer na Ďumbieri“ (Abend auf dem Dumbier) aus Rúfus' erwähntem Debüt gibt es einen imaginären Dialog mit einem toten, gefallenen Soldaten, der zeichenhaft durch ein Denkmal in den Bergen vertreten ist. Die Situation „vojak zrútil sa a zaspal na úbočí (Der Soldat brach zusammen und schlief im Winkel ein) erinnerte Viliam Marčok, den Verfasser einer Rúfus-Monografie, an Arthur Rimbauds „Der Schläfer im Tal“. Bei Rúfus heißt es:

do žliabku v doline vytiekol jeho hlas.

Vták z neho napil sa, vták píska v kosodreví.

A d’alej zostáva a oslovuje nás. (Rúfus 1956: 70)

ins Rinnsal im Tal rann seine Stimme. / Ein Vogel daraus trank, der Vogel pfeift im Krummholz. / Und bleibt und spricht uns an.

Das ist eine ästhetische „Versöhnung“ von Leben und Tod, Verlust und Genugtuung. In Mikuláš Kováčs Gedicht „Oswienćin 1958“5 (Auschwitz 1958) aus der Sammlung „Zem pod nohami“ (1960, Erde unter den Füßen) stellt die Beschreibung der dortigen Museumsexposition, die man Ende der 1950er Jahre auch von der Tschechoslowakei aus besuchte, einen Katalog dar, eine Aufzeichnung von Dingen, Namen, Adressen und von dem, was die Menschen hinterlassen hatten oder was von ihnen geblieben war - bereits ohne ihre lebendige Gegenwart:

${ }^{5} \mathrm{Zu}$ den Umständen der Entstehung des Gedichts und zum damaligen Kontakt des Autors mit Ján Ondruš gibt eine Passage in Mikuláš Kováčs poetologischer Konfession Poznámky o vol'nom verši (Bemerkungen zum freien Vers) Auskunft (vgl. Kováč 1989). 
A kde zostali vaše hlasy?

Je ticho,

je vel'ké ticho na tejto zemi.

Vták,

ktorý bol vtákom, ked’ sme boli mladí,

vták, ktorý bol škrekl’avým mäsom,

ked' sme hladom zomierali,

vták,

ktorý sa z našej krvi napil,

spieva našim hlasom.

Počujete? (Kováč 1960: 24-25)

Und wo blieben eure Stimmen? // Es ist still, / es ist eine große Stille auf dieser Erde. // Der Vogel, / der ein Vogel war, da wir jung waren, / der Vogel, der kreischendes Fleisch war, / da wir hungers starben, / der Vogel, / der unser Blut trank, // singt mit unserer Stimme. // Hört ihr?

Bei aller Symmetrie in der Aufzählung handelt es sich hier eher um eine anästhetische Kakophonie des nicht wieder Gutzumachenden. Bei Ondruš blieb vom Vogelmotiv die Synekdoche der Flaumfeder. Die im Refrain wiederholten selbstproblematisierenden Fragen steigern sich zu einem Rufen, die Motivik des Defizitären, das „ewig lyrische“ Zuspätkommen des sich erinnernden Sprechers schält sich heraus:

prv než som klesajúce pierko

svojím hlasom zachytil a opät' dvíhal;

než som tú pieseň zo zeme

vzal ako kameň a v l'ahkej dlani stískal - (Ondruš 1962: 25)

bevor ich die sinkende Flaumfeder / mit meiner Stimme auffing und wieder emporhob, / bevor ich dieses Lied von der Erde / nahm wie einen Stein und in der leichten Hand drückte -

Die Formulierung von der Stimme, die sich verfängt und dann aufgefangen wird, legt einen Vergleich mit Jozef Mihalkovič nahe, der Jahrzehnte später das Gewicht oder die „Leistung“ der Poesie und des Nachdenkens über sie als „,sich Verfangen in Sprache“ bezeichnete. Sind die Flaumfeder (die „Feder“ als Homonymie zur Schreibfeder?), die Stimme und das Lied Synonyme der Poesie oder des schöpferischen Tuns schlechthin? Sollten Stimme und Lied als immer noch utopisches Paradigma des lyrischen oder poetischen Elements fungieren, trotz all der modernisierenden Transformationen? Wären Ondrušs ,Stimmen“ demzufolge nicht nur ein Familiengedicht im Sinne der Generationenfolge, nicht nur ekstatisch auf das Tätigsein orientiert, sondern verborgen poetologisch? - Der Kollaps und das Ende in der Generation des Vaters wird als Variation auf den Kollaps und das Ende des Großvaters wiedergegeben. Das Durchbrennen und Erlöschen der Glühlampe als technische Chiffre für Ende und Tod (das sich „Verheizen“ in Arbeit, das Erlöschen des Lebens) lässt an die in Ondrušs Generation schon aus der Schule bekannten letzten 
Verse von Jiří Wolkers „Balada o očích topičových“ (Ballade von den Augen des Heizers) denken:

Dělník je smrtelný,

práce je živá,

Antonín umíra,

žárovka zpívá [...]. (Wolker 1953: 145-146)

(Der mensch verstummt, / sein werk erklingt, / Anton stirbt, / die Glühbirne singt ...) (Übers. Reiner Kunze in Chvatík 1991: 154)

Ondruš wertet aber die Motivik des technisch säkularisierten „ewigen Lichtes“, das einen energetischen Zuschuss von der „lebendigen Arbeit“ erhält, durch seine Poetik des Defizitären radikal um und hebt sie nahezu auf. Diese - nicht unproblematische - freie Assoziation verweist zumindest darauf, dass ähnlich wie in Wolkers sozialer Ballade auch die schicksalhafte Generationenfolge in den „Stimmen“ balladisch modelliert wurde.

Bei diesem provisorischen Gang durch das Gedicht „Stimmen“ haben sich vorläufige, bisweilen disparate Bestimmungen angeboten: Es wurde als Porträtgedicht mit Ansätzen zur Monumentalisierung definiert, das zwischen der Ekstatik der Arbeit und der bedrohten Idylle des Zuhause oszilliert, als diskretes lyrisches Autoporträt eines sich erinnernden Sprechers, das im Zeichen einer Selbstproblematisierung steht, als poetologisches Gedicht oder als balladisch-,familiärer" Schicksalsgesang, als durchgehend phonisch-vokalisch-musikalisches Element, das sich emporschwingt und niedergeschlagen-melancholisch ausklingt ...

Was die Gattungsbestimmung des Gedichts anbelangt, so kann man mit einer an dieser Stelle sicher zulässigen Vereinfachung und vor dem Hintergrund der slowakischen 1960er Jahre einerseits über eine Tendenz zum „Langgedicht“ mit einer hochkomplizierten Struktur sprechen, wobei dieses „Langgedicht“ in der Tradition der Apollinaireschen „Zone“ und seiner nachfolgenden Modifikationen die Ambition aufweist, ein Kaleidoskop der modernen Welt und auch den ambivalenten menschlichen Anteil an ihr vorzuführen; oder es möchte aus oftmals bedrückenden, mäandrisch gegliederten Handlungsfragmenten, überhaupt aus der „Last“ des individuellen Lebens und seiner „Verstrickung“ in den Gang der Welt anhand von Bildchiffren oder direkter Reflexion das seltene, schimmernde Leuchten von Sinn zu Tage fördern. Auf der anderen Seite finden wir auch die Tendenz zum „Kurzgedicht“ mit einer gnomisch kondensierten Erfahrung, mit einer Beispielhaftigkeit synekdochischer Situationen oder andeutungsweise konstituierter Figuren. Als Beispiele aus dem slowakischen Kontext ließen sich für das Langgedicht etwa die „Štyri knihy nepokoja“ (Vier Bücher der Beunruhigung) von Miroslav Válek (1927-1991) anführen, die als einzelne Sammlungen zwischen 1959 und 1965 erschienen, oder die „Zimoviská“ (1965, Winterlager) von Jozef Mihalkovič. Als Beispiel für das Kurzgedicht sei die Sammlung „Zvony“ (1968, Glocken) von Milan Rúfus genannt. Diese vereinfachende Verkürzung dient hier lediglich dazu, auf einen Grenzbereich mit 
einer Vielzahl von Formen zu verweisen, die sich für eine flüchtige Identifikation anbieten.

Bei Ondrušs „Stimmen“ kann man zudem von einer Vielstimmigkeit, von einer Polyphonie des Textes sprechen: direkte Stimmen-Figurenrepliken, Refrain-Variationen, Variationen von Gnomen und vorgestellten Schlüsselsituationen, ein stilistisches Register, das von einer geradezu gestischen Expressivität oder Aggressivität bis zu einem lyrischen Abflauen und Ausklingen reicht, und ein durchgängig phonisch-vokalisch-musikalisches Element, das durch das Bild der „Orgel“ thematisiert und kondensiert wird. ${ }^{6}$ - Der familiengeschichtliche thematische Hintergrund ging erst nach einer gewissen Bearbeitung durch Auswahl und Verschiebung in das Gedicht ein. Wie das Kalendarium von Ondrušs Leben oder biographische Materialien bezeugen, die auch die Vorgeschichte von Ondrušs Familie und das Schicksal verschiedener Angehöriger in den historischen Wechselfällen jener komplizierten Jahrzehnte des vergangenen Jahrhunderts enthalten, gäbe es hier hinreichend Material für eine Familiensaga in Prosa, ein Genre, das mit mehr oder weniger Erfolg auf ähnlicher Materialgrundlage auch in der slowakischen Literatur der vergangenen Jahrzehnte gepflegt wurde. Ondruš jedoch konzentrierte die Mannigfaltigkeit kraft der Intensität seiner Bildhaftigkeit und Sprache zu einer - dichterischen Fuge.

${ }^{6}$ Die Überlegung, wie das Gedicht im Grenzbereich von Körper, Körperlichkeit und Zeichenhaftigkeit zu situieren wäre, knüpft an die Frage nach den „Stimmen“ an. Als Schlüssel zu Ondrušs Gedicht „Pamät"“ konnte ich eine elementare körperliche Selbst-Bewegung des lyrischen Subjekts im Sinne einer Selbst-Orientierung und Selbst-Wahrnehmung evidieren, die einer Berührung, eines Kontaktes mit den Elementen, mit der Erde, der Sonne und den Dingen bedarf (vgl. Matejov 1986). Die Synthetisierung und Differenzierung des Erfahrenen geht dann in einen „höheren“ Bereich kulturell-kommunikativer Aktivitäten über. Zusammenfassend kann das alles als „Kinästhesie“ bezeichnet werden - ein etwas magisch wirkendes Wort aus dem Kontext der Phänomenologie der leiblichen Wahrnehmung, wie sie etwa durch Ludwig Landgrebe oder Jan Patočka nach Edmund Husserl formuliert wurde (weniger magisch und etwas ,ziviler“" klänge der lateinische Ausdruck „Sensomotorik“). Von dieser Inspiration ausgehend fragte ich nach der Intentionalität des durch die Verben ausgedrückten Geschehens in seiner subtilen lexikalisch-grammatischen Gestalt: Was bedeutet es, diese vor-sprachliche, stumme Erfahrung dichterisch zu erschließen und zu artikulieren, was bedeutet es konkret für die lyrische Stimmführung, für die Intonation und die Syntax, für den freien Vers, für den Prozess des Schreibens, die graphische Konfiguration des Textes? Auch in diese Richtung ließen sich weiterführende Überlegungen anstellen.

7 Peter Zajac nannte auch den von Sigmund Freud geprägten Begriff der „Trauerarbeit“, den ich bei der Analyse von Ondrušs Gedicht „Sobota“ (Samstag) pointiert eingesetzt habe (vgl. Matejov 2005). Ich habe hier, um Wiederholungen zu vermeiden, darauf verzichtet, bin aber umso dankbarer für die Erwähnung dieses möglichen Zugangs zur Interpretation des Gedichts. Die Abfolge der „Todesfälle“ (des Großvaters, des Vaters) im thematischen Geschehen des Gedichts führt zur Frage hin, wer im Sinne der Generationen- und Todesfolge, aber auch einer aus Märchen, Balladen oder dem Aberglauben bekannten Dreigliedrigkeit nun der verschwiegene Dritte sein soll? Der sich selbst problematisierende, sich erinnernde Sprecher? Der lyrische Text nicht nur als „Trauerarbeit“, sondern auch als das verschwiegene Beschwören der Furcht vor dem Unabwendbaren? Im Zusammenhang mit der Gattungsbestimmung des Gedichts als Fuge erwähnte Zajac den Titel des be- 
Der Gang durch Ondrušs „Stimmen“ sei - einschließlich der riskanten Pointe Pavol Winczer als Leser und Lyrik-Interpreten gewidmet, der bei aller methodisch kontrollierten Sachlichkeit wohl immer ein Freund und Enthusiast der Poesie geblieben ist. Die Exkurse an den Rand und in das Hinterland des Gedichts sollten sich mit einigen Bleistiftstrichen an dem aktuellen Vorhaben beteiligen, das Bild der slowakischen Poesie des 20. Jahrhunderts neu zu zeichnen, in denen sie die Strecke von der historischen Avantgarde über die Neoavantgarde der späten 1950er und 1960er Jahre als einer paradoxerweise immer noch innovativen, bereichernden, originellen „Wiederholung“ des anscheinend ewig „Neuen“ bis zur Postavantgarde zurücklegte, wo nunmehr das Bewusstsein von der Abgeschlossenheit einer bestimmten Ära und Angelegenheit die Poesie auf Wege führt, für die wir geschichtlich und literaturgeschichtlich nicht nur auf Grund ihrer deklarierten, sondern ihrer tatsächlich ausgeprägten Gestalt gerade erst dabei sind, eine Sprache zu finden.

\section{Anhang}

Ján Ondruš

Hlasy

Odkladám husle,

predstavujem si starého otca, kováča.

Čo tento sláčik,

pohyb pred tvárou?

Vidím starého otca, ako zastavil tancujúceho koňa,

ako mu skrútol nohu bez kolena, pálil kopyto, dychčal,

vyrážal vety $\mathrm{k}$ prizerajucim, skončil,

odišiel,

l'ahol si.

Čo moja smietka

z oka vypadnutá?

Zavolal: Katarína! Stará mat' bežkala, neskoro prišla. Vystretý, ako oheň čierny, nad jeho hlavou zimnične sa triasla

v žiarovke cievka pretrhnutá.

kanntesten Gedichts von Paul Celan (1920-1970), die „Todesfuge“, an die ich natürlich gedacht hatte, dies aber aus Zurückhaltung gegenüber dem deutschsprachigen Leser nicht so direkt formulieren wollte. Es soll aber zumindest klar gestellt werden, dass diese Überlegungen nicht um Fragen literarischer Kontakte kreisen, sondern bei aller Verschiedenheit des Sujets vor allem auf die polyphone Poetik sowie das musikalische und subtile Motiv der Schwebe abzielen. 
Je pieseň, po piesni je mlčanie.

To sa odmlčal môj starý otec, kováč.

Čo tu môj

sláčik?

Otec, tiež kováč, ráno vstával, vyšiel,

vrátil sa po uterák, svitalo,

a povedal: Svitá. Svitá, hovorí. A tak prišla chvíla

(to už nepovedal)

urobit' podkovu ako zlatú korunku,

spievat' a volat', stúpat' na pedál

(organu, ktorý iskrí, horí,

syčí žeravou píšt'alou, kone pri ňom kričia),

utriet' dym vo vlasoch, máchnut' ramenom,

až letí vejár kvapiek, každá v horúčosti

dopadá na zem v podobe zrnka soli,

večer vojst' do kuchyne, naberat' si z misy,

zložit' lyžicu, zamysliet' sa a nepovedat': Žijem.

Vediet' to a nepovedat': Žijem, žijem,

to je tá pravá chvíl'a, miesto, ponúknutie

raz udriet', udriet' tisíc ráz,

tak ako nikto

udriet' kladivom!

Čo tento sláčik,

pohyb pred tvárou?

Čo tento náznak

zakrývania očí?

Zložil lyžicu, vstal.

Vstal a plesol dverami. A zazrel

a vstal a plesol a bol by

bil, tíkol hánkami, bol by sa zahnal

rukou ako predíženou kladivom a azda by bol pl'ul

ponad kuchynský stôl, hrnce a cibul'u,

do myších kútov, na čipky a kvietky,

tulipán vyšívaný,

nesmiete, nechytajte ho za kabát,

za rukáv nerdžiavajte -

a plesol dverami a stíchlo a za ním

ako cvaknutie kl'učky začal plač.

Ach, aké piesne títo l'udia spievali!

Ach, ako zaznel v týchto ústach spev!

Ako znel! Ako sa spiekli slová tejto piesne!

Po kusoch leteli. Bili to tvárí,

do pŕs strkali, prevrhli, šliapali,

ale aj zmäkli na odpoved', našli si v tráve cestičku,

jediné pierko na hlase sa zachytilo, 
plávalo, klesalo, oknom vyletelo

pod bledú oblohu, kde vietor pieseň sfúkol.

Čo táto smietka,

pohyb pred tvárou?

Čo tento sláčik,

zakrývanie očí?

Je pieseň, po piesni jej mlčanie.

Mlčí ju, mlčí ju môj otec, kováč.

Smietočka! Sláčik!

Prv než som prišiel, než som mohol zbadat', na čo uprene hl'adí nad strechami, prv než som klesajúce pierko

svojím hlasom zachytil a opät' dvíhal;

než som tú pieseň zo zeme

vzal ako kameň a v l'ahkej dlani stískal -

zavolal: Pavlína! Mat' bežkala,

nestihla. Vystretý, ako oheň čierny,

nad jeho sluchou žilke podobá sa

$\mathrm{v}$ žiarovke nitka pretrhnutá.

Smietočka,

sláčik ...

Mat' vraví: Otec,

No, otec!

Otec!

(Ondruš 1962)

\section{Stimmen}

Ich lege die Geige beiseite,

stelle mir Großvater vor, den Schmied.

Weshalb dieser Bogen,

die Bewegung vorm Gesicht?

Ich sehe den Großvater, wie er das tanzende Pferd anhielt,

ihm das Bein ohne Knie drehte, das Hufeisen brannte, keuchte,

den Gaffern Sätze hinspie, aufhörte,

fortging,

sich niederlegte.

Weshalb mein Splitter,

der aus dem Auge fiel?

Er rief: Katarína! Großmutter trippelte herbei, zu spät. Ausgestreckt, schwarz wie das Feuer, über seinem Kopf zitterte im Schüttelfrost der in der Glühbirne zerrissene Faden. 
Es ist das Lied, nach dem Lied ist das Schweigen.

Mein Großvater war verstummt, der Schmied.

Weshalb hier

mein Geigenbogen?

Vater, ebenfalls Schmied, pflegte früh aufzustehen, er trat heraus,

kam zurück das Handtuch zu holen, es dämmerte,

und er sagte: Es dämmert. Es dämmert, sagte er. Und so kam der Moment

(das sagte er nicht mehr)

ein Hufeisen zu fertigen wie eine goldene Krone,

zu singen und zu rufen, in das Pedal zu treten

(der Orgel, die Funken sprüht, brennt,

aus glühenden Pfeifen zischt, dass die Pferde brüllen),

Rauch ins Haar zu reiben, den Arm zu schwenken,

bis ein Tropfenfächer fliegt, jeder Tropfen landet fiebernd

auf der Erde in der Form eines Salzkorns,

abends in die Küche kommen, aus der Schüssel schöpfen,

den Löffel beiseite legen, nachdenken und nicht sagen: Ich lebe.

Es wissen und nicht sagen: Ich lebe, ich lebe,

das ist der rechte Moment, der Ort, das Anerbieten,

einmal zuzuschlagen, tausendmal zuzuschlagen,

so wie niemand (sonst)

mit dem Hammer zu schlagen!

Weshalb dieser Geigenbogen,

die Bewegung vorm Gesicht?

Weshalb diese Andeutung

Des Bedeckens der Augen?

Er legte den Löffel beiseite, stand auf.

Stand auf und knallte die Tür zu. Und er blickte finster

und er stand auf und knallte und er hätte

geschlagen, gepocht mit den Fingergelenken, hätte ausgeholt

mit dem Arm wie mit einem verlängerten Hammer und vielleicht hätte er gespieen

über den Küchentisch, über Tasse und Zwiebel,

in die Mauswinkel, auf Spitzen und Blümchen,

auf die gestickte Tulpe,

ihr dürft nicht, fasst ihm nicht an die Jacke,

zieht nicht am Ärmel -

und er knallte die Tür zu und es ward still und nach ihm

begann wie das Klacken der Klinke ein Weinen.

Ach, was für Lieder diese Menschen sangen!

Ach, wie klang in diesen Mündern der Gesang!

Wie er klang! Wie sich die Worte dieses Lieds zusammenbuken!

Sie flogen stückweise. Schlugen ins Gesicht, rammten die Brust, sie stürzten, trampelten, ließen sich aber auch zur Antwort erweichen, fanden im Gras einen Pfad, eine einzige Flaumfeder verfing sich in der Stimme, 
schwamm, sank, flog aus dem Fenster

unter den fahlen Himmel, wo der Wind das Lied ausblies.

Weshalb dieser Splitter,

die Bewegung vorm Gesicht?

Weshalb dieser Geigenbogen,

das Bedecken der Augen?

Es ist ein Lied, nach dem Lied ist das Schweigen des Liedes.

Der es schweigt ist mein Vater, der Schmied.

Splitterchen! Geigenbogen!

Bevor ich kam, bevor ich merken konnte,

was er über den Dächern anstarrt,

bevor ich die sinkende Flaumfeder

mit meiner Stimme auffing und wieder emporhob,

bevor ich dieses Lied von der Erde

nahm wie einen Stein und in der leichten Hand drückte -

rief er: Pavlína! Mutter trippelte herbei,

schaffte es nicht. Ausgestreckt, schwarz wie das Feuer,

der Ader über seiner Schläfe ähnelt

in der Glühbirne der zerrissene Faden.

Splitterchen,

Geigenbogen ...

Mutter sagt: Vater,

na, Vater!

Vater!

\section{Literatur}

Bokníková-Tóthová 2006: Andrea Bokníková-Tóthová (Hrsg.), Trnavská skupina - konkretisti, Bratislava

Chvatík 1991:

Květoslav Chvatík (Hrsg.), Die Prager Moderne, Frankfurt am Main

Eliade 1978:

Mircea Eliade, Geschichte der religiösen Ideen Bd. 1 (Von der Stein-

Kindler ${ }^{3} 2009$ :

zeit bis zu den Mysterien von Eleusis), Freiburg im Breisgau

Kováč 1960:

Stichwort Ján Ondruš. Das lyrische Werk, in: Heinz Ludwig Arnold

Kováč 1989:

Mikuláš Kováč, Zem pod nohami, Bratislava

Matejov 1986:

Mikuláš Kováč, Poznámky o vol'nom verši, Dotyky Jg. 1, Nr. 10, 3637

Matejov 2005:

Fedor Matejov, Báseň Jána Ondruša „Pamät“, in: Valér Mikula und Peter Zajac (Hrsg.), Literárne rozhl'ady, Bratislava, 164-185

Mihalkovič 1962:

Fedor Matejov, Lyrika ako „paradigma“ lektúry, in: Ders., Lektúry, Bratislava, 9-36

Ondruš 1962:

Ondruš 1965:

Rúfus 1956:

Jozef Mihalkovič, Lútost', Bratislava

Ján Ondruš, Hlasy, Slovenské pohl'ady, Jg. 78, 1962, Nr. 9, 23-25

Ján Ondruš, Šialený mesiac, Bratislava

Milan Rúfus, Až dozrieme, Bratislava

Winczer 1968:

Pavol Winczer, Ján Ondruš. Studňa, in: Ján Kopal und Pavol Plutko (Hrsg.), O Interpretácii umeleckého textu Bd. 1, Nitra, 39-48 
Wolker 1953:

Zajac 2004:

Jiří Wolker, Básně, Praha

Peter Zajac, Slovenská literatúra ako dobrodružstvo, in: Ders., Krajina bez sna, Bratislava, 57-78. In der englischsprachigen Kurzfassung: Peter Zajac, Slovak literature as an Adventure, in: Stanislava Chrobáková (Hrsg.), One Hundred Years of Slovak Literature. An Anthology, Bratislava 2000, 14-22

Czesław Zgorzelski, Možnosti žánrovéh
Slovenská literatúra Jg. 28, Nr. 4, 372-381

A b st r a c t: The Poem "Hlasy" by Ján Ondruš in the Context of Young Slovak Poetry of the 1950s and early 1960s. Reflections on theme and poetic genre provides an interpretation of "Hlasy" by Ondruš, a long poem that is representative of trends in Slovak poetry of the 1960 s and whose themes and motifs are also analysed in relation to contemporary poetry. Ultimately, reflections on poetic genre lead to the conclusion that this is a complex, polyphonic poetic work that is richly ambiguous in every respect.

K e y w ords : Ján Ondruš, Hlasy, Concretist artists, Trnavská skupina, Slovak Poetry, neo- and post avant-garde, long poem, polyphony, fugue

Fedor Matejov

Ústav slovenskej literatúry SAV

Konventná 13

81364 Bratislava, Slowakei 
